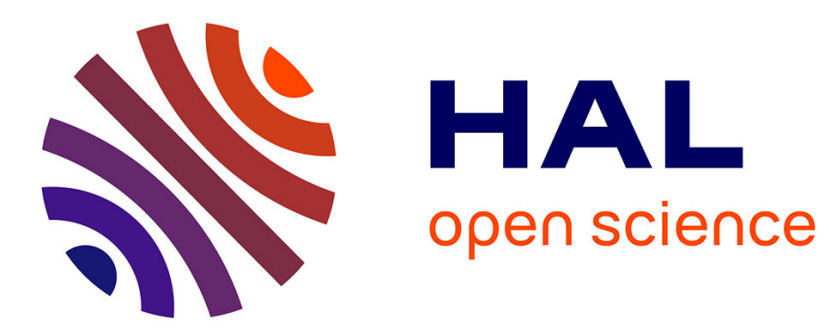

\title{
Continuous Cauchy wavelet transform of XAFS spectra.
}

\author{
Manuel Munoz, François Farges, Pierre Argoul
}

\section{To cite this version:}

Manuel Munoz, François Farges, Pierre Argoul. Continuous Cauchy wavelet transform of XAFS spectra.. Physica Scripta, 2005, 115, pp.221-222. 10.1238/Physica.Topical.115a00221 . hal-00101965

\section{HAL Id: hal-00101965 https://hal.science/hal-00101965}

Submitted on 28 Sep 2006

HAL is a multi-disciplinary open access archive for the deposit and dissemination of scientific research documents, whether they are published or not. The documents may come from teaching and research institutions in France or abroad, or from public or private research centers.
L'archive ouverte pluridisciplinaire HAL, est destinée au dépôt et à la diffusion de documents scientifiques de niveau recherche, publiés ou non, émanant des établissements d'enseignement et de recherche français ou étrangers, des laboratoires publics ou privés. 


\title{
CONTINUOUS CAUCHY WAVELET TRANSFORM OF XAFS SPECTRA
}

\author{
M. Muñoz ${ }^{1}$, F. Farges ${ }^{1,2 *}$ and P. Argoul ${ }^{3}$ \\ ${ }^{1}$ Laboratoire des Géomatériaux, Université de Marne-La-Vallée, CNRS FRE 2455, 77454 Marne-La- \\ Vallée cedex 2, France \\ ${ }^{2}$ Department of Geological and Environmental Sciences, Stanford University, CA 94305-2115, USA \\ ${ }^{3}$ Laboratoire Analyse des Matériaux et Identification, Unité Mixte ENPC-LCPC, 77455 Marne-La-Vallée \\ cedex 2, France
}

\begin{abstract}
The continuous Cauchy wavelet transform (CCWT) is applied to the analysis of XAFS spectra. Thanks to that method, XANES and EXAFS signals can be visualized in threedimension: the wavevector $(k)$, the interatomic distance uncorrected for phase-shifts $\left(R^{\prime}\right)$ and the CCWT modulus (corresponding to the continuous decomposition of the amplitude terms). Applied to EXAFS spectra, the CCWT analysis provides straightforward qualitative information related to the $k$-range of each " $R$ '-EXAFS" contribution. Such information is particularly useful to perform next nearest-neighbors identification, despite the presence of spectral artifacts such as multiple-scattering features, multi-electronic excitations or noise. When applied to XANES spectra, the CCWT analysis helps highly to measure the "spectral limit" between XANES and EXAFS regions, as well as the energy range required to model properly next-nearest neighbors. To further illustrate the potential of CCWT analyses applied to XAFS spectra, we present examples related to: (1) a XANES spectrum collected at the Ti $K$-edge for titanite $\left(\mathrm{CaTiSiO}_{5}\right)$; (2) an experimental $\mathrm{Au} L_{\mathrm{III}}$-edge EXAFS spectrum for gold sorbed on goethite $(\mathrm{FeO}(\mathrm{OH}))$.
\end{abstract}

PACS ref: 61.10.Ht, 02.30.Nw, 07.05.Kf

* e-mail: farges@univ-mlv.fr 


\section{Introduction}

X-ray absorption fine structure (XAFS) spectroscopy (including XANES and EXAFS regions) is a powerful tool for investigating the short-, and medium range environment around a selected absorbing atom in structurally complex materials like ceramics, glasses and solutions. However, the experimental signals can be complicated due to the overlapping of several contributions such as single-scattering (SS), multiple-scattering (MS) and, among others, multielectronic excitations. Usually, Fourier transform (FT) methods are used to obtain a frequency decomposition of the normalized EXAFS signal. However, FT analyses only provide a onedimensional decomposition in the $R^{\prime}$-space (interatomic distances uncorrected for phase-shifts) of the data processed in the $k$-space (wavevector). Here, we present a continuous wavelet transform approach [1], providing a two-dimensional representation of the analyzed signal (e.g., a "timefrequency" correlation). More particularly, we use the continuous Cauchy wavelet transform (CCWT), which was recently proven to be successful for analyzing EXAFS signals in a twodimensional $(k, R$ ')-space [2]; the third dimension (i.e., the CCWT modulus) representing the amplitude terms to within a wavelet-defined constant. Details on the theory of the method and the choice of the Cauchy "mother-wavelet" are explained in [2] and [3].

\section{Application to XANES and EXAFS spectra}

The Fig. 1 presents a CCWT modulus (2D and 3D), calculated between 0.2 and $6.0 \AA$, for the Ti $K$-edge XANES spectrum of crystalline titanite $\left(\mathrm{CaTiSiO}_{5}\right.$; data from [4]). The XANES spectrum was previously converted into $k$-space, and normalized using cubic splines, like for an EXAFS spectrum. Thanks to the $\left(k, R^{\prime}\right)$ decomposition, the CCWT modulus clearly distinguish the "XANES" region (coming essentially from first-neighbors MS events near $3.5 \AA$ ), from the "EXAFS" region (where the SS events from distant-neighbors dominate, e.g., near 1.5 $\AA$ ). Note that the FT analysis only provides an average magnitude between both regions and then, underestimates drastically the signal in the "XANES" region. This example shows the particular 
interest of a $\left(k, R^{\prime}\right)$ representation, as compared to a direct space representation $\left(R^{\prime}\right)$ provided by conventional FT analyses.

The Fig. 2 presents the analysis (2D and 3D CCWT modulus) of an experimental $\mathrm{Au} L_{\mathrm{III}}{ }^{-}$ edge $k^{3}$-weighted EXAFS spectrum, collected for gold sorbed on a goethite $(\mathrm{FeOOH})$; data from [5]). The CCWT modulus, calculated between 0.2 and $6.0 \AA$, shows a second neighbors contribution (ridge C) occurring for high $k$-values, which suggests the presence of "heavy" atoms (i.e., high atomic number) in that coordination shell [2]. However, based on other evidences (see [5] for details), $\mathrm{Au}$ atoms cannot be located in the next-nearest environment around gold. Consequently, the CCWT modulus highlights an important destructive interaction (see region B) between, at least, two EXAFS contributions. Based on a detailed analysis of the EXAFS spectrum [5], the first contribution is related to " $\mathrm{Au}-\mathrm{O}$ " MS events, whereas the other one is related to $\mathrm{Au}-\mathrm{Fe} \mathrm{SS}$ events. Also, the CCWT analysis shows the importance, in that specific case, to collect data up to $16 \AA^{-1}$ in order to get significant contributions from the distant Fe atoms. 


\section{REFERENCES}

[1] Chui, C.K., "An Introduction to Wavelets" (Academic Press, London 1992), p. 264.

[2] Muñoz, M., Argoul, P. and Farges, F., Am. Mineral 88, 694 (2003).

[3] Argoul, P. and Le, T.-P., Mech. Syst. Signal Process. 17, 243 (2003).

[4] Farges, F., Am. Mineral. 82, 44 (1997).

[5] Berrodier, I. et al., Geochim. Cosmochim. Acta (2003), submitted. 


\section{FIGURE CAPTIONS}

Fig. 1. CCWT analysis for a Ti $K$-edge XANES spectrum of titanite, (up) 2D modulus; (down) 3D modulus. Note that on the FT magnitude, the intensity of " $\mathrm{B}$ " is averaged over the $k$-range $0-9 \AA^{-1}$, whereas its intensity is higher than " $\mathrm{A}$ " (i.e., first neighbors contribution) in the low $k$-region (see "XANES" on the CCWT modulus).

Fig. 2. CCWT analysis for a $\mathrm{Au} L_{I I I}$-edge EXAFS spectrum of gold sorbed on goethite, (up) 2D modulus; (down) 3D modulus. Note the destructive interference "B" between the MS from the oxygen first neighbors, and the SS from the iron second neighbors. Note also that collecting data up to $16 \AA^{-1}$ is required to model robustly the $\mathrm{Au}-\mathrm{Fe}$ pairs. 


\section{FIGURE 1}
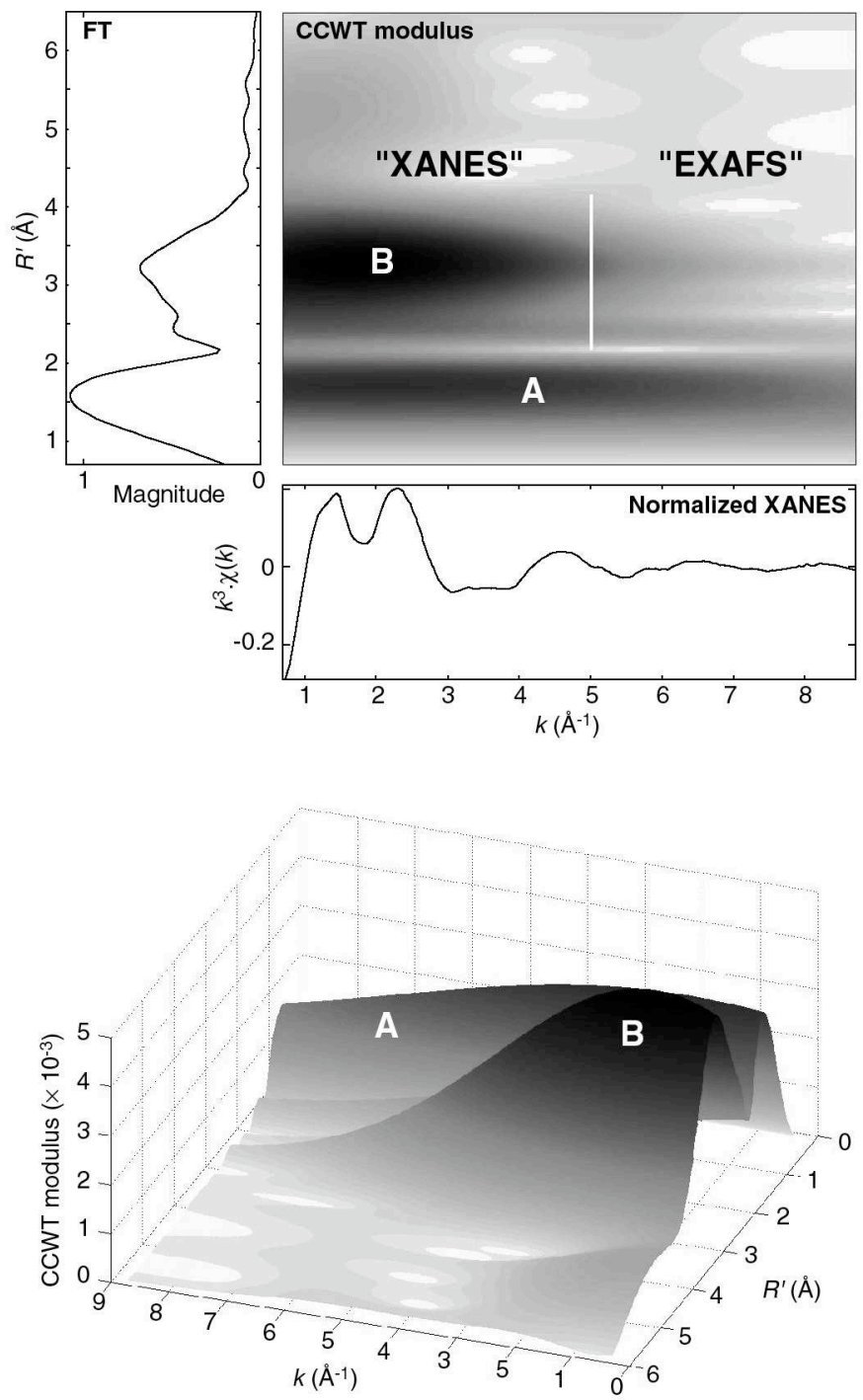


\section{FIGURE 2}
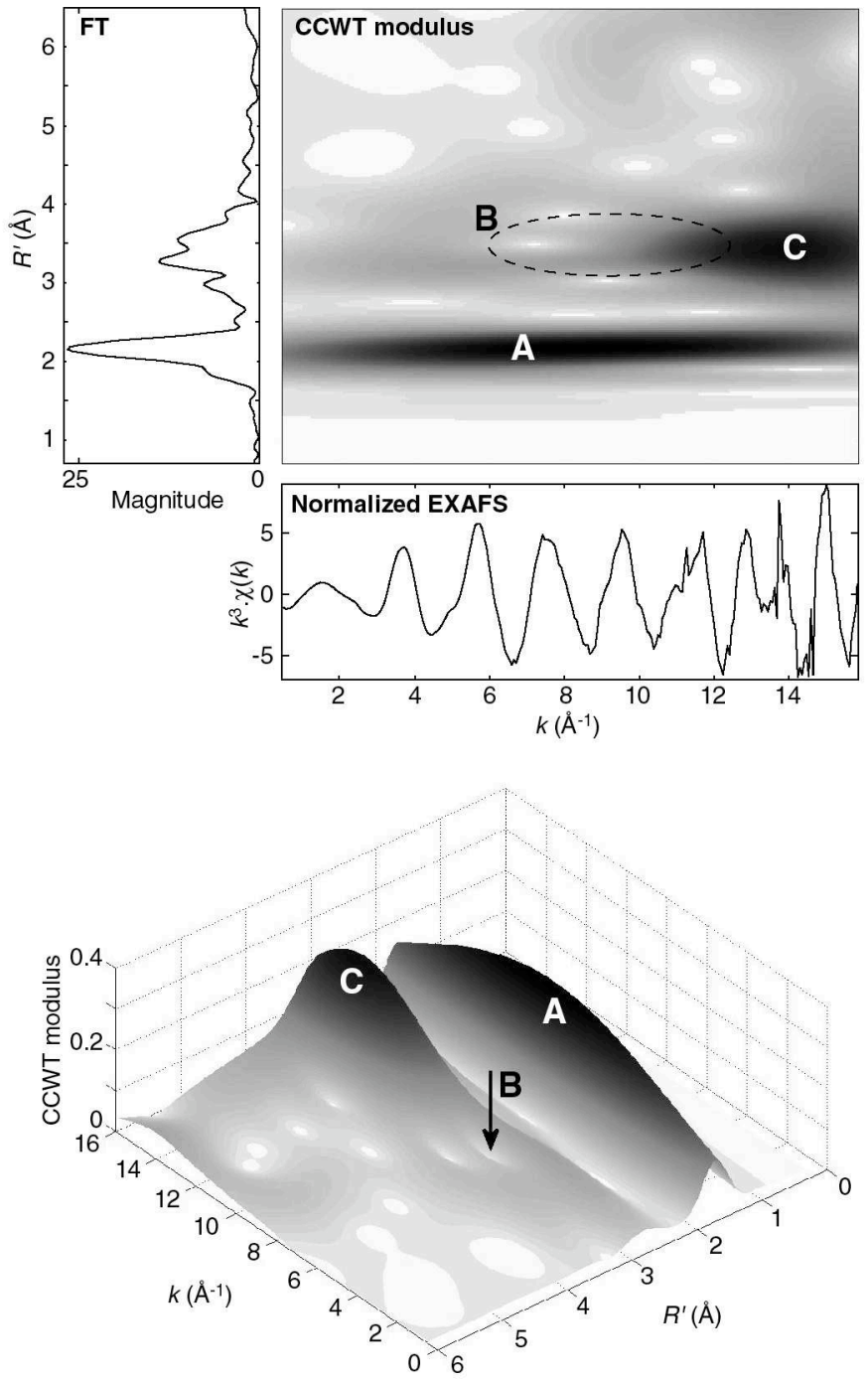